\title{
Article \\ Advanced Glycation End Products Impair Cardiac Atrial Appendage Stem Cells Properties
}

\author{
Lize Evens ${ }^{1}$, Ellen Heeren ${ }^{1} \mathbb{D}$, Jean-Luc Rummens ${ }^{1,2}$, Annelies Bronckaers ${ }^{1}$, Marc Hendrikx ${ }^{1} \mathbb{D}$, \\ Dorien Deluyker ${ }^{1,+}$ and Virginie Bito ${ }^{1, *,+(\mathbb{D})}$ \\ 1 BIOMED, UHasselt-Hasselt University, Agoralaan, 3590 Diepenbeek, Belgium; lize.evens@uhasselt.be (L.E.); \\ ellen.heeren@student.uhasselt.be (E.H.); jeanluc.rummens@uhasselt.be (J.-L.R.); \\ annelies.bronckaers@uhasselt.be (A.B.); marc.hendrikx@uhasselt.be (M.H.); \\ dorien.deluyker@uhasselt.be (D.D.) \\ 2 Faculty of Medicine and Life Sciences, UHasselt-Hasselt University, Agoralaan, 3590 Diepenbeek, Belgium \\ * Correspondence: virginie.bito@uhasselt.be; Tel.: +32-1126-9285 \\ + Both authors equally contributed.
}

Citation: Evens, L.; Heeren, E.; Rummens, J.-L.; Bronckaers, A.; Hendrikx, M.; Deluyker, D.; Bito, V. Advanced Glycation End Products Impair Cardiac Atrial Appendage Stem Cells Properties. J. Clin. Med. 2021, 10, 2964. https://doi.org/ $10.3390 / \mathrm{jcm} 10132964$

Academic Editor: Francesco Angelini

Received: 1 June 2021

Accepted: 29 June 2021

Published: 1 July 2021

Publisher's Note: MDPI stays neutral with regard to jurisdictional claims in published maps and institutional affiliations.

Copyright: (c) 2021 by the authors. Licensee MDPI, Basel, Switzerland. This article is an open access article distributed under the terms and conditions of the Creative Commons Attribution (CC BY) license (https:// creativecommons.org/licenses/by/ $4.0 /)$.

\begin{abstract}
Background: During myocardial infarction (MI), billions of cardiomyocytes are lost. The optimal therapy should effectively replace damaged cardiomyocytes, possibly with stem cells able to engraft and differentiate into adult functional cardiomyocytes. As such, cardiac atrial appendage stem cells (CASCs) are suitable candidates. However, the presence of elevated levels of advanced glycation end products (AGEs) in cardiac regions where CASCs are transplanted may affect their regenerative potential. In this study, we examine whether and how AGEs alter CASCs properties in vitro. Methods and Results: CASCs in culture were exposed to ranging AGEs concentrations $(50 \mu \mathrm{g} / \mathrm{mL}$ to $400 \mu \mathrm{g} / \mathrm{mL})$. CASCs survival, proliferation, and migration capacity were significantly decreased after $72 \mathrm{~h}$ of AGEs exposure. Apoptosis significantly increased with rising AGEs concentration. The harmful effects of these AGEs were partially blunted by pre-incubation with a receptor for AGEs (RAGE) inhibitor ( $25 \mu \mathrm{M}$ FPS-ZM1), indicating the involvement of RAGE in the observed negative effects. Conclusion: AGEs have a time- and concentration-dependent negative effect on CASCs survival, proliferation, migration, and apoptosis in vitro, partially mediated through RAGE activation. Whether anti-AGEs therapies are an effective treatment in the setting of stem cell therapy after MI warrants further examination.
\end{abstract}

Keywords: stem cells; aldehyde dehydrogenase; CASCs; glycated proteins; advanced glycation end products; proliferation; apoptosis; migration; RAGE inhibition

\section{Introduction}

Coronary heart disease (CHD) remains the leading cause of mortality and morbidity worldwide, with myocardial infarction (MI) being the most common form of CHD [1]. MI results from complete or partial occlusion of a coronary artery. In the ischemic area, oxygen and nutrients are restricted, resulting in myocardial cell death. The infarct size depends on multiple factors, such as the size of the ischemic area at risk, the location and duration of coronary occlusion, and the amount of residual collateral blood flow [1,2]. As adult cardiomyocytes have minimal regenerative properties, intrinsic repair of the damaged tissue remains elusive. Finding a therapeutic approach that effectively replaces myocardial scar with functional contractile tissue is the only option to recover lost cardiac tissue.

Much research effort has been put into unravelling the therapeutic potential and mechanisms of cell therapy with bone marrow cells (BMCs). Bone marrow contains hematopoietic stem cells (HSCs), endothelial progenitor cells (EPCs), and mesenchymal stem cells (MSCs) [3]. Clinical trials with mononuclear BMCs and MSCs failed to deliver significant improvements in post-MI cardiac function. As mononuclear BMCs and MSCs do not differentiate into cardiomyocytes, the limited improvements observed are likely 
to be attributed to paracrine mechanisms [4,5]. To significantly improve post-MI cardiac function, the focus of research shifted towards resident cardiac stem cells (CSCs) such as c-kit+, Sca-1+-, Isl-1+-cells, and cardiospheres, who are likely to be pre-programmed to become cardiomyocytes. Yet, their success in cardiac regeneration is poor [6].

In the last years, our research group discovered a new type of cardiac stem cells named 'cardiac atrial stem cells' (CASCs). In contrast to other stem cells, CASCs display extraordinary cardiomyogenic differentiation properties, making them a promising candidate for cardiac regeneration [4]. Isolation of this stem cell population from atrial appendages is based on high aldehyde dehydrogenase (ALDH) activity. High ALDH activity was also reported in other stem cell types, like MSCs, HSCs, neural and cancer stem cells amongst others [7-9]. Since ALDH has proven to be cardioprotective and promotes cell survival in stress conditions, using an $\mathrm{ALDH}^{+}$stem cell population in ischemic conditions may be, in this context, beneficial $[4,10]$. CASCs can be expanded up to clinically relevant numbers, without losing fundamental characteristics, such as ALDH activity, surface antigen profile, and its cardiomyogenic differentiation capacity [11]. This given is crucial for translation of this therapeutic approach to the clinic. In addition, we have shown that autologous CASCs transplantation results in improved left ventricular function, resulting from adequate stem cell engraftment and further CASCs differentiation [4,12].

In MI patients, levels of advanced glycation end-products (AGEs) are increased [13]. AGEs are proteins and/or lipids that are irreversibly damaged by glycation, a process in which reducing sugars react non-enzymatically with amino groups in lipids or proteins. Besides glycation, oxidative stress also leads to AGEs formation through oxidation of proteins and/or lipids [14]. AGEs are formed endogenously and naturally accumulate in the body with senescence or in pathological situations such as MI, when levels of oxidative stress are increased [15-17]. Furthermore, previous research has shown that AGEs affect different types of stem cells in vitro [18-20]. The capacity of stem cells to proliferate is reduced by AGEs, and the apoptotic rate is increased upon AGEs application. These effects could be executed throughout several mechanisms, including activation of the apoptotic pathway, RAGE, or excessive ROS formation [20]. Whether AGEs also affect CASCs properties remains unknown. These findings raise the question whether AGEs could negatively influence the therapeutic efficacy of CASCs, which are used as a treatment for MI. The aim of this study is therefore to examine the in vitro effects of AGEs and the potential activation of its receptor RAGE on proliferation, survival, and migration of CASCs.

\section{Materials and Methods}

\subsection{Animal Experiments}

Animal studies were conducted in accordance with the EU Directive 2010/63/EU for animal experiments and approved by the Local Ethical Committee for Animal Experimentation (UHasselt, Belgium, Diepenbeek; ID 201919K). All animals were kept in a temperature-controlled environment $\left(21^{\circ} \mathrm{C}, 60 \%\right.$ humidity) with a $12 \mathrm{~h}-12 \mathrm{~h}$ light-dark cycle. They were fed a standard pellet diet with water available ad libitum. In total, 62 female Sprague-Dawley rats (Janvier Labs, Le Genest-Saint-Isle, France) were used.

\subsection{Rat CASCs Isolation and Expansion}

CASCs were harvested from the right atrial appendages, as described before [4]. Briefly, rats were injected with heparin (1000 units / kg, intraperitoneally (i.p.)) and were euthanized with an overdose of sodium pentobarbital (Dolethal, Vetoquinol, Aartselaar, Belgium, $200 \mathrm{mg} / \mathrm{kg}$, i.p.). Hearts were harvested, perfused with a normal Tyrode solution $(137 \mathrm{mM} \mathrm{NaCl}, 5.4 \mathrm{mM} \mathrm{KCl}, 0.5 \mathrm{mM} \mathrm{MgCl} 2,1 \mathrm{mM} \mathrm{CaCl} 2,11.8 \mathrm{mM} \mathrm{Na}-\mathrm{HEPES}, 10 \mathrm{mM}$ glucose, $20 \mathrm{mM}$ taurine, $\mathrm{pH}$ 7.4), and the right atrial appendages were collected. The extracted right atrial appendage tissue was minced in pieces of $\sim 1 \mathrm{~mm}^{3}$, washed with phosphate buffered saline (PBS), and enzymatically dissociated for $30 \mathrm{~min}$ in Hank's Balanced Salt Solution containing $0.6 \mathrm{WU} / \mathrm{mL}$ collagenase NB 4 (Serva, Heidelberg, Germany) and $20 \mathrm{mM}$ 
$\mathrm{CaCl}_{2}$. ALDH ${ }^{+}$cells were stained according to the Aldefluor kit (STEMCELL Technologies, Evergem, Belgium). $\mathrm{ALDH}^{+}$cells were defined as CASCs and were flow-sorted (BD FACS Aria) in X-VIVO 15 media (Lonza, Basel, Switzerland) supplemented with $20 \%$ fetal calf serum (FCS) and $2 \%$ penicillin/streptomycin (P/S). Isolated CASCs were seeded in 6-well plates at a density of 60,000 cells per well and incubated at $37^{\circ} \mathrm{C}$ in a humidified incubator with a $5 \% \mathrm{CO}_{2}$ atmosphere. Medium was changed every 2 to 3 days. When CASCs reached $80 \%$ confluence, they were harvested using trypsin. For all experiments, passage 1 CASCs were used.

\subsection{AGEs Preparation}

AGEs were prepared as previously described [21]. Briefly, bovine serum albumin (BSA; $7 \mathrm{mg} / \mathrm{mL}$ ) was incubated with glycolaldehyde dimers (90 mM; Sigma-Aldrich, Diegem, Belgium) in sterile PBS ( $\mathrm{pH}$ 7.4) for 5 days at $37^{\circ} \mathrm{C}$. This solution was dialyzed against PBS, two times for $2 \mathrm{~h}$ and overnight at $4{ }^{\circ} \mathrm{C}$ to remove unreacted glycolaldehyde (3.4 kDa cut-off). AGEs were filtered (0.2 $\mu \mathrm{m}$ filter, Sarstedt, Antwerp, Belgium). BSA incubated in PBS $(7 \mathrm{mg} / \mathrm{mL})$ was used as a control solution.

\subsection{Proliferation and Survival Assay}

Proliferation and survival assays were executed, with a propidium iodide (PI) assay as described before by Gervois et al. and Lo Monaco et al. [22,23]. Briefly, CASCs were seeded in a 96-well plate in X-VIVO medium with 10\% FCS and $2 \% \mathrm{P} / \mathrm{S}$. For proliferation assays, 5000 cells per well were seeded. For survival assays, 10,000 cells per well were seeded. After $24 \mathrm{~h}$, five different conditions were added to the medium: $400 \mu \mathrm{g} / \mathrm{mL} \mathrm{BSA}$, $50 \mu \mathrm{g} / \mathrm{mL}, 100 \mu \mathrm{g} / \mathrm{mL}, 200 \mu \mathrm{g} / \mathrm{mL}$, and $400 \mu \mathrm{g} / \mathrm{mL}$ AGEs. To measure proliferation, BSA or AGEs were added to X-VIVO medium with $2 \%$ FCS and $2 \% \mathrm{P} / \mathrm{S}$. To measure survival, BSA or AGEs were added to X-VIVO medium with $0 \% \mathrm{FCS}$ and $2 \% \mathrm{P} / \mathrm{S}$. After three different time points $(24,48$, and $72 \mathrm{~h})$, the medium was replaced with Lysis buffer A100 (ChemoMetec, Kaiserslautern, Germany), followed by an equal amount of stabilization buffer B (ChemoMetec) supplemented with PI (10 $\mu \mathrm{g} / \mathrm{mL}$, Sigma). Following an incubation period of $15 \mathrm{~min}$ in the dark, fluorescence was measured using the Fluostar Optima plate reader (BMG Labtech, Ortenberg, Germany) at an excitation of $540 \mathrm{~nm}$, emission wavelength of $612 \mathrm{~nm}$, and a gain of 2000. Experiments were performed in triplicate. Data were normalized to data obtained with $400 \mu \mathrm{g} / \mathrm{mL}$ BSA.

\subsection{Migration Assay}

CASCs were seeded in a 12-well plate at a density of 50,000 cells per well in X-VIVO medium with $10 \%$ FCS and $2 \% \mathrm{P} / \mathrm{S}$. Five conditions were added to the medium: $400 \mu \mathrm{g} / \mathrm{mL}$ BSA, $50 \mu \mathrm{g} / \mathrm{mL}, 100 \mu \mathrm{g} / \mathrm{mL}, 200 \mu \mathrm{g} / \mathrm{mL}$, and $400 \mu \mathrm{g} / \mathrm{mL}$ AGEs. After an incubation period of $72 \mathrm{~h}$, the conditioned CASCs were harvested using trypsin and used for a transwell migration assay. In the ThinCerts (Greiner Bio-One, Vilvoorde, Belgium) with a porous membrane of $8 \mu \mathrm{m}$ pore size, 100,000 cells per condition were seeded in X-VIVO medium with $0 \%$ FCS and $2 \% \mathrm{P} / \mathrm{S}$. ThinCerts were placed onto 24-well plates containing X-VIVO medium with $2 \%$ FCS and $2 \% \mathrm{P} / \mathrm{S}$. After $24 \mathrm{~h}$ of migration, the ThinCerts were fixated with $4 \%$ paraformaldehyde (PFA) for $15 \mathrm{~min}$ and incubated with $0.1 \%$ crystal violet for $30 \mathrm{~min}$. Cells that did not migrate were removed at the top side of the ThinCerts, after which the amount of transmigrated CASCs was quantified with AxioVision 4.6 software (Carl Zeiss, Zaventem, Belgium). Data were normalized to data obtained with $400 \mu \mathrm{g} / \mathrm{mL}$ BSA.

\subsection{Apoptosis Assay}

CASCs were seeded in a 96-well plate at a density of 10,000 cells per well in X-VIVO medium with $2 \%$ FCS and $2 \% \mathrm{P} / \mathrm{S}$. To study apoptosis, a caspase assay was performed using the IncuCyte ${ }^{\circledR}$ Caspase-3/7 Green Apoptosis Assay Reagent (diluted 1/1000, Sartorius, Schaarbeek, Belgium). Five conditions were added to the medium: $400 \mu \mathrm{g} / \mathrm{mL}$ BSA, $50 \mu \mathrm{g} / \mathrm{mL}, 100 \mu \mathrm{g} / \mathrm{mL}, 200 \mu \mathrm{g} / \mathrm{mL}$, and $400 \mu \mathrm{g} / \mathrm{mL}$ AGEs. CASCs cultured in X-VIVO 
medium without FCS and 2\% P/S were used as a positive control. Experiments were performed in triplicate. Images were taken after 24,48 , and $72 \mathrm{~h}$ of incubation using the IncuCyte $^{\circledR}$ S3 Live-Cell Analysis System (Sartorius, Schaarbeek, Belgium). Analysis of the area occupied by apoptotic cells was performed using the IncuCyte ${ }^{\circledR}$ SX1 Live-Cell Analysis System (Sartorius, Schaarbeek, Belgium). Data were normalized to the positive control (+, X-VIVO medium without FCS).

\subsection{In Vitro RAGE Inhibition}

RAGE was inhibited to assess the contribution of RAGE activation in proliferation, survival, and migration of CASCs. Briefly, CASCs were pre-incubated at $37{ }^{\circ} \mathrm{C}$ in a $5 \%$ $\mathrm{CO}_{2}$ incubator with the RAGE antagonist FPS-ZM1 (10 and $25 \mu \mathrm{M}$, Calbiochem/Merck, Overijse, Belgium). After $2 \mathrm{~h}^{\prime}$ pre-incubation, $400 \mu \mathrm{g} / \mathrm{mL}$ AGEs were added. After 24, 48 , and $72 \mathrm{~h}$, proliferation and survival were evaluated as described above. After $72 \mathrm{~h}$ of incubation, pre-conditioned CASCs were harvested and used for a transwell migration assay as described above.

\subsection{Statistics}

Statistical analyses were performed using GraphPad Prism 9.0.0 software. Normal distribution of data was assessed with the Shapiro-Wilk test. Normally distributed data were subjected to a one-way ANOVA test with repeated measurements, followed by the Holm-Sidak's Multiple Comparison test. When data were not normally distributed, the non-parametrical Friedman test was used followed by the Dunn's Multiple Comparison test. All data are expressed as mean \pm standard error of the mean (SEM). A value of $p<0.05$ was considered statistically significant.

\section{Results}

\subsection{AGEs Exposure Negatively Affects CASCs Proliferation and Survival}

As shown in Figure 1, AGEs significantly and gradually decreased CASCs proliferation over time. The negative impact of AGEs on CASCs proliferation was also concentrationdependent. After $72 \mathrm{~h}$, concentrations of $100 \mu \mathrm{g} / \mathrm{mL}, 200 \mu \mathrm{g} / \mathrm{mL}$, and $400 \mu \mathrm{g} / \mathrm{mL}$ AGEs significantly reduced CASCs proliferation compared to BSA (Figure $1 \mathrm{C} ; 80 \% \pm 7$ in $100 \mu \mathrm{g} / \mathrm{mL}$, $74 \% \pm 3$ in $200 \mu \mathrm{g} / \mathrm{mL}$, and $65 \% \pm 4$ in $400 \mu \mathrm{g} / \mathrm{mL}$ AGEs). Application of BSA alone did not affect the proliferative capacity of CASCs (Figure S1 in Supplementary Materials).
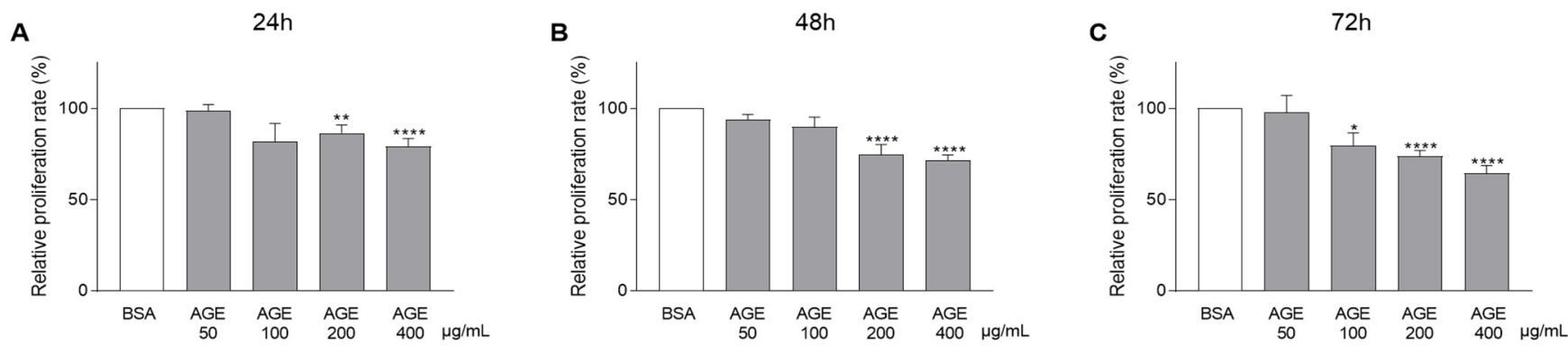

Figure 1. Rising concentrations of AGEs gradually reduce CASCs proliferation. CASCs were exposed to different AGEs concentrations $(50,100,200$, and $400 \mu \mathrm{g} / \mathrm{mL})$. Proliferation was measured at different time points: $24 \mathrm{~h}((\mathbf{A}), n=18), 48 \mathrm{~h}$ $((\mathbf{B}), n=18)$, and $72 \mathrm{~h}((\mathbf{C}), n=21)$. Data are normalized to BSA and represented as mean \pm SEM. ${ }^{*}$ denotes $p<0.05$, ** denotes $p<0.01, * * *$ denotes $p<0.0001$ vs. BSA.

As shown in Figure 2, rising concentrations of AGEs negatively affected CASCs survival in time. Significant effects of AGEs were observed after 48 (Figure 2B) and $72 \mathrm{~h}$ (Figure 2C; 85\% \pm 3 in $100 \mu \mathrm{g} / \mathrm{mL}, 73 \% \pm 3$ in $200 \mu \mathrm{g} / \mathrm{mL}$, and $64 \% \pm 4$ in $400 \mu \mathrm{g} / \mathrm{mL}$ AGEs). Application of BSA alone did not affect the survival capacity of CASCs (Figure S1). 


\section{A}

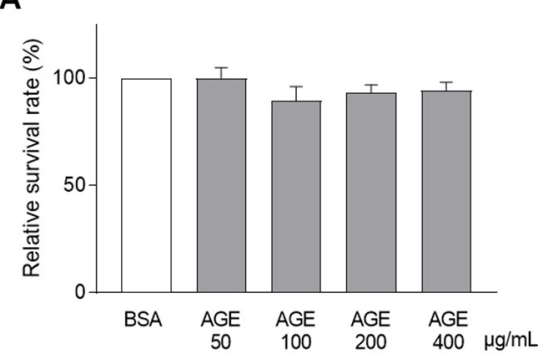

$48 \mathrm{~h}$

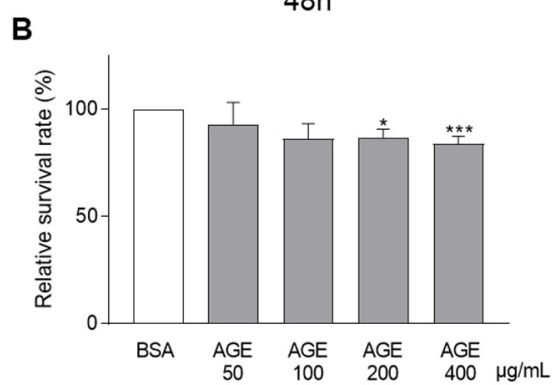

C

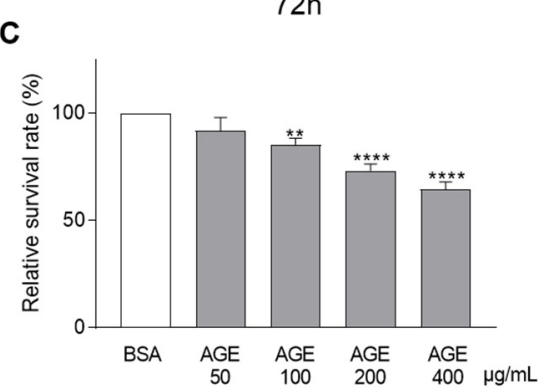

Figure 2. Rising concentrations of AGEs reduced CASCs survival over time. CASCs were exposed to different AGEs concentrations $(50,100,200$, and $400 \mu \mathrm{g} / \mathrm{mL})$. Survival was measured at different time points: $24 \mathrm{~h}((\mathbf{A}), n=28), 48 \mathrm{~h}((\mathbf{B})$, $n=20)$, and $72 \mathrm{~h}((\mathbf{C}), n=25)$. Data are normalized to BSA and represented as mean \pm SEM. ${ }^{*}$ denotes $p<0.05, * *$ denotes $p<0.01{ }^{* * *}$ denotes $p<0.0011^{* * * *}$ denotes $p<0.0001$ vs. BSA.

\subsection{Increased AGEs Concentrations Increase CASCs Apoptosis}

To elucidate the effect of different AGEs concentrations $(50,100,200$, and $400 \mu \mathrm{g} / \mathrm{mL})$ on CASCs apoptosis, a caspase assay was performed. The percentage of cells expressing caspase 3/7 was measured at different time points: 24 (Figure 3A), 48 (Figure 3B), and 72 (Figure 3C) h. Apoptotic rate gradually increased over time with increased AGEs concentrations (Figure 3C, $72 \mathrm{~h} ; 77 \% \pm 17$ in $400 \mu \mathrm{g} / \mathrm{mL}$ AGEs vs. 18\% \pm 3 in BSA).

A

$24 \mathrm{~h}$

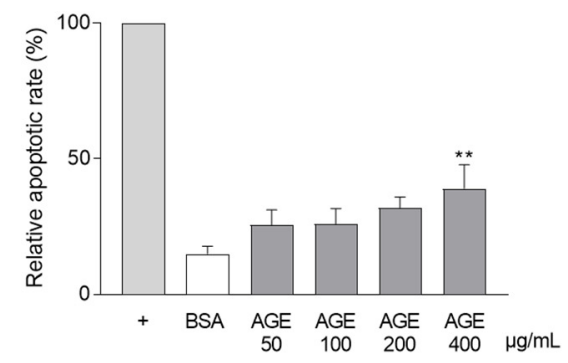

B

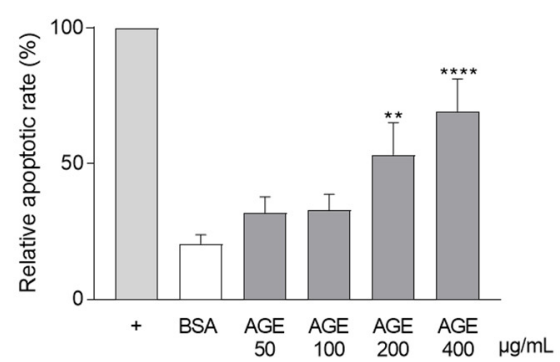

C

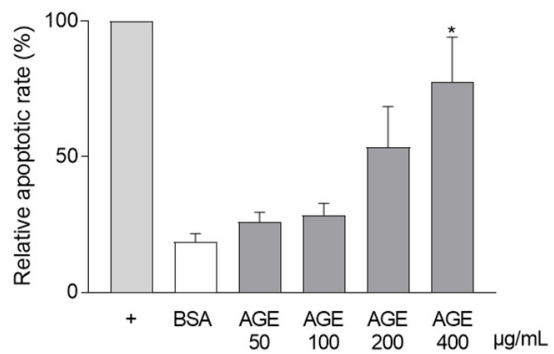

Figure 3. Rising AGEs concentrations increases CASCs apoptosis. CASCs were conditioned with BSA and rising concentrations of AGEs $(50,100,200$, and $400 \mu \mathrm{g} / \mathrm{mL})$. The percentage of apoptosis was measured over time for $24((\mathbf{A}), n=6), 48$ $((\mathbf{B}), n=8)$, and $72 \mathrm{~h}((\mathbf{C}), n=7)$. Data are normalized to the positive control $(+, \mathrm{X}-\mathrm{VIVO} 0 \% \mathrm{FCS}, 2 \% \mathrm{P} / \mathrm{S})$ and shown as mean \pm SEM. ${ }^{*}$ denotes $p<0.05,{ }^{* *}$ denotes $p<0.01,{ }^{* * * *}$ denotes $p<0.0001$ vs. BSA.

\subsection{AGEs Exposure Decreases CASCs Migration Capacity}

CASCs migration capacity was evaluated with a transwell migration assay after $72 \mathrm{~h}$ of incubation with different concentrations of AGEs. In Figure 4A-E, representative examples of CASCs migration after incubation with BSA and different AGEs concentrations (50, 100, 200, and $400 \mu \mathrm{g} / \mathrm{mL}$ ) are presented. Quantification of migration is shown in Figure $4 \mathrm{~F}$. Compared to BSA, a significant reduction in migration was observed when CASCs were incubated with $400 \mu \mathrm{g} / \mathrm{mL}$ AGEs (Figure 4E,F; 75\% \pm 5 in $400 \mu \mathrm{g} / \mathrm{mL}$ AGEs). 

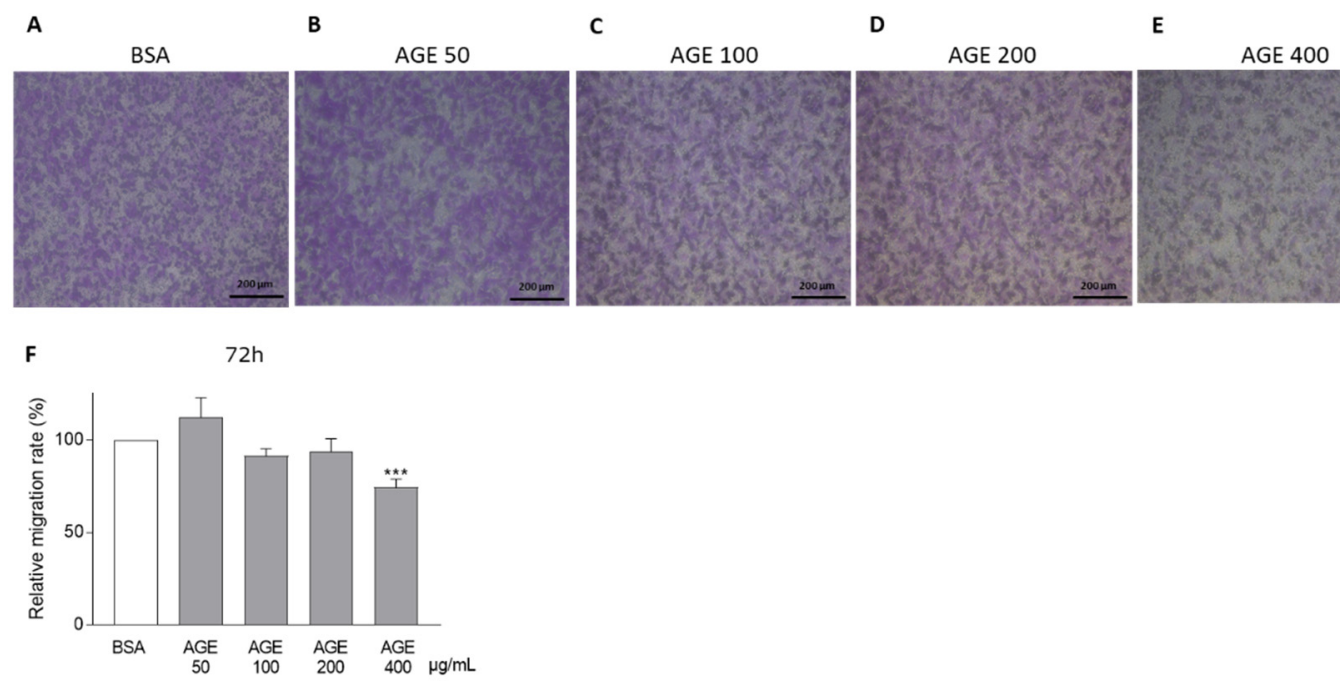

Figure 4. AGEs reduce CASCs migration capacity. Representative examples of CASCs migration when incubated for $72 \mathrm{~h}$ with (A) BSA and different AGEs concentrations: (B) $50 \mu \mathrm{g} / \mathrm{mL},(\mathbf{C}) 100 \mu \mathrm{g} / \mathrm{mL}$, (D) $200 \mu \mathrm{g} / \mathrm{mL}$, and (E) $400 \mu \mathrm{g} / \mathrm{mL}$. Scale bar $=200 \mu \mathrm{m}$. (F) Quantification of CASCs migration after $72 \mathrm{~h}$ of incubation with different AGEs concentrations. Fifty $\mu \mathrm{g} / \mathrm{mL}(n=6), 100 \mu \mathrm{g} / \mathrm{mL}(n=10), 200 \mu \mathrm{g} / \mathrm{mL}(n=6)$, and $400 \mu \mathrm{g} / \mathrm{mL}$ AGEs $(n=20)$. Data are normalized to BSA and shown as mean \pm SEM. ${ }^{* *}$ denotes $p<0.001$ vs. BSA.

\subsection{Deleterious Effects of AGEs in CASCs Are Mediated by RAGE Activation}

To evaluate the contribution of RAGE activation in the observed deleterious effects of AGEs, proliferation, survival, and migration of CASCs were assessed after the incubation with the RAGE antagonist FPS-ZM1. Before exposure to $400 \mu \mathrm{g} / \mathrm{mL}$ AGEs, CASCs were pre-incubated for $2 \mathrm{~h}$ with 10 or $25 \mu \mathrm{M}$ FPS-ZM1. Application of FPS-ZM1 alone (10 and $25 \mu \mathrm{M}$ ) did not affect the proliferative capacity nor the survival of CASCs (Figure S2).

CASCs proliferation (Figure 5A-C) was evaluated after 24 (A), 48 (B), and 72 (C) h. As shown in Figure 1, the negative impact on CASCs proliferation by AGEs is significantly blunted after pre-incubation with $25 \mu \mathrm{M}$ FPS-ZM1 (Figure 5A-C). Indeed, after 24 and $48 \mathrm{~h}$, CASCs proliferation was significantly improved, with $400 \mu \mathrm{g} / \mathrm{mL}$ AGEs exposure (24 h, Figure $5 \mathrm{~A} ; 104 \% \pm 8$ in $25 \mu \mathrm{M}$ FPS-ZM1 vs. $79 \% \pm 5$ in $400 \mu \mathrm{g} / \mathrm{mL}$ AGEs; $48 \mathrm{~h}$, Figure 5B; $95 \% \pm 5$ in $25 \mu \mathrm{M}$ FPS-ZM1 vs. $70 \% \pm 4$ in $400 \mu \mathrm{g} / \mathrm{mL}$ AGEs). After $72 \mathrm{~h}$, the same trend was observed. Proliferation tended to improve when RAGE was inhibited (Figure $5 \mathrm{C} ; 80 \% \pm 8$ in $25 \mu \mathrm{M}$ FPS-ZM1 vs. $67 \% \pm 5$ in $400 \mu \mathrm{g} / \mathrm{mL}$ AGEs, $p=0.06$ ).

A

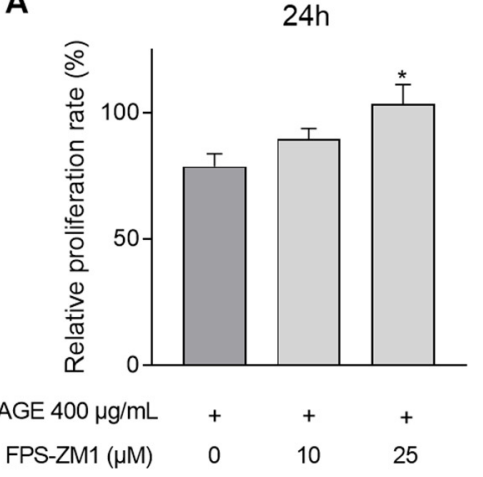

B

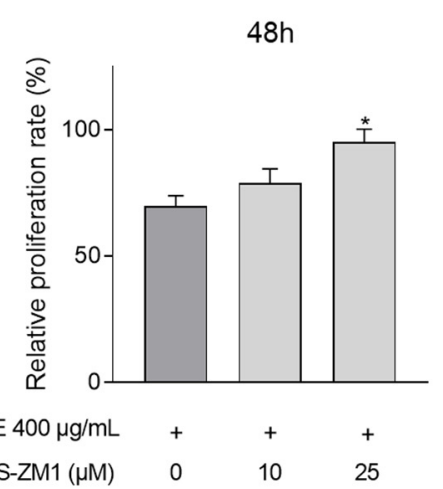

C

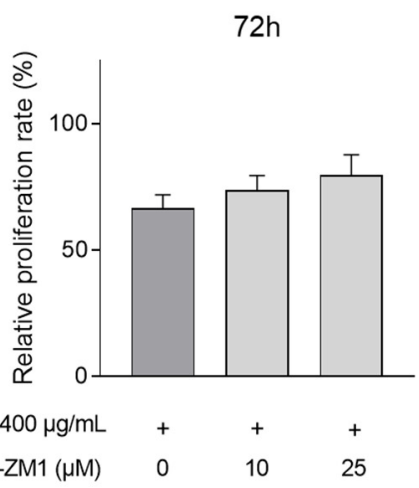

Figure 5. CASCs proliferation is improved when blocking RAGE. CASCs were exposed to $400 \mu \mathrm{g} / \mathrm{mL}$ AGEs. In addition, CASCs were pre-incubated with 10 or $25 \mu \mathrm{M}$ FPS-ZM1. Proliferation was measured at different time points: $24((\mathbf{A}), n=13)$, $48((\mathbf{B}), n=12)$, and $72 \mathrm{~h}((\mathbf{C}), n=15)$. Data are normalized for BSA and represented as mean \pm SEM. ${ }^{*}$ denotes $p<0.05$ vs. $400 \mu \mathrm{g} / \mathrm{mL}$ AGEs. 
Survival (Figure 6A-C) was evaluated after 24 (A), 48 (B), and 72 (C) h. The negative impact on CASCs survival by AGEs (Figure 2) is significantly improved after pre-incubation with $25 \mu$ M FPS-ZM1 (Figure 6A-C). After $24 \mathrm{~h}$, survival significantly improved (Figure 6A; $104 \% \pm 7$ in $25 \mu \mathrm{M}$ FPS-ZM1 vs. $91 \% \pm 4$ in $400 \mu \mathrm{g} / \mathrm{mL}$ AGEs). This trend was also observed after $48 \mathrm{~h}$ (Figure $6 \mathrm{~B} ; 91 \% \pm 5$ in $25 \mu \mathrm{M}$ FPS-ZM1 vs. $81 \% \pm 5$ in $400 \mu \mathrm{g} / \mathrm{mL}$ AGEs, $p=0.07$ ).

A

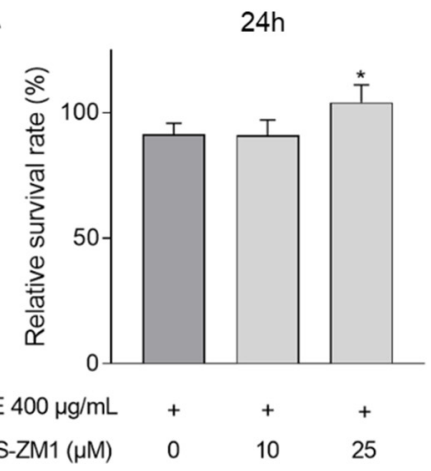

B

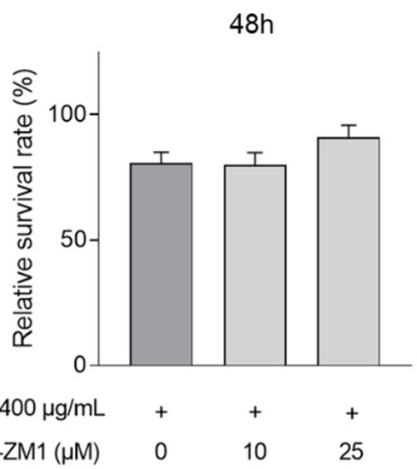

C

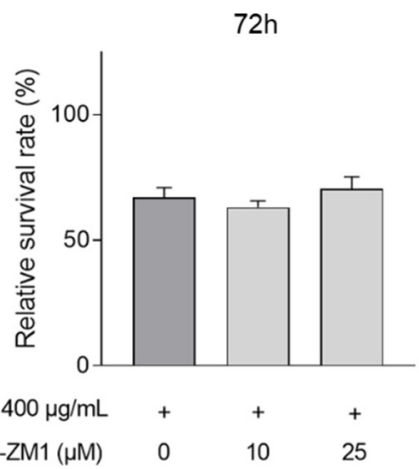

Figure 6. RAGE inhibition improved CASCs survival. CASCs were exposed to $400 \mu \mathrm{g} / \mathrm{mL}$ AGEs. In addition, CASCs were pre-incubated with 10 or $25 \mu \mathrm{M}$ FPS-ZM1. Survival was measured at different time points: $24((\mathbf{A}), n=14), 48((\mathbf{B}), n=12)$, and $72 \mathrm{~h}((\mathbf{C}), n=15)$. Data are normalized for BSA and represented as mean \pm SEM. ${ }^{*}$ denotes $p<0.05 \mathrm{vs} .400 \mu \mathrm{g} / \mathrm{mL}$ AGEs.

Representative examples of CASCs migration after $72 \mathrm{~h}$ incubation with $400 \mu \mathrm{g} / \mathrm{mL}$ AGEs and FPS-ZM1 are presented in Figure 7A and quantified in Figure 7B. CASCs preincubation with $25 \mu \mathrm{M}$ FPS-ZM1 could prevent the decreased CASCs migration capacity observed with AGEs exposure (Figure 7B; $98 \% \pm 6$ in $25 \mu \mathrm{M}$ FPS-ZM1 vs. $77 \% \pm 8$ in $400 \mu \mathrm{g} / \mathrm{mL}$ AGEs, $p=0.07$ ).

A

AGE 400

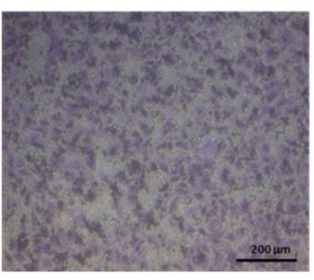

AGE $400+$ $10 \mu \mathrm{M}$ FPS-ZM1

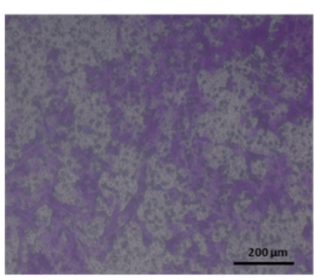

AGE $400+$ $25 \mu \mathrm{M}$ FPS-ZM1

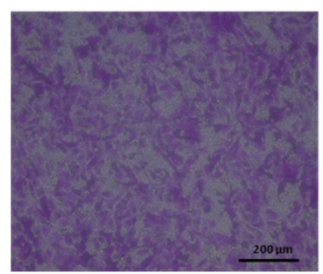

B

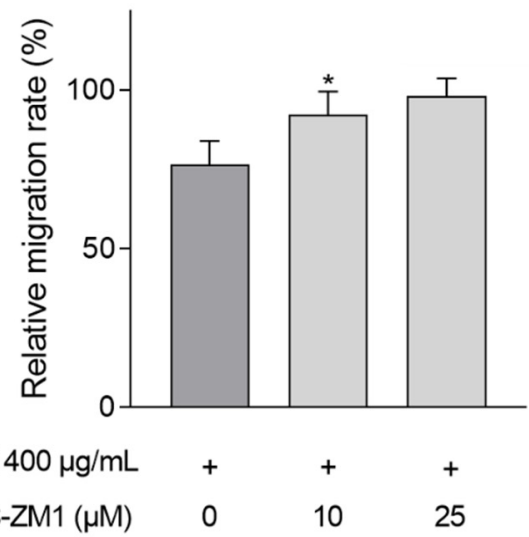

Figure 7. RAGE inhibition improves CASCs migration. (A) Representative examples of CASCs migration when incubated for $72 \mathrm{~h}$ with $400 \mu \mathrm{g} / \mathrm{mL}$ AGEs and pre-incubated with 10 or $25 \mu \mathrm{M}$ FPS-ZM1. Scale bar $=200 \mu \mathrm{m}$. (B) Quantification of CASCs migration $(n=11)$ when incubated with $400 \mu \mathrm{g} / \mathrm{mL}$ AGEs and pre-incubation with 10 or $25 \mu \mathrm{M}$ FPS-ZM1 for $72 \mathrm{~h}$. Data are normalized for BSA and represented as mean \pm SEM. ${ }^{*}$ denotes $p<0.05 \mathrm{vs.} 400 \mu \mathrm{g} / \mathrm{mL}$ AGEs.

\section{Discussion}

Our study is the first to show that AGEs affect CASCs properties, namely survival, proliferation, migration, and apoptosis in vitro. Our data demonstrate that these effects are partially mediated through RAGE activation in a dose-dependent manner. 


\subsection{The Role of AGEs in MI}

Circulatory AGEs levels are significantly elevated in patients with acute MI [24,25]. However, how they are involved in the pathophysiology of MI remains unclear. Reactive oxygen species (ROS) are the main contributors involved in the synthesis of AGEs. Oxidative stress can induce formation of reactive carbonyl compounds and glycoxidation of Amadori products in the Maillard reaction. As such, AGEs are irreversibly formed and accumulated in the heart after MI and are thought to potentially further worsen the adverse cardiac phenotype [26,27]. In addition, neutrophils and activated macrophages, involved in the inflammatory process in MI, are major contributors of AGEs synthesis [28,29]. These immune cells secrete AGEs and are reported as key inducers of AGEs formation in MI.

\subsection{Physiological Relevance of AGEs Concentrations}

In our study, we tested a broad range of AGEs concentrations (50 to $400 \mu \mathrm{g} / \mathrm{mL}$ ). The AGEs concentration used in other in vitro studies investigating the effect of AGEs on stem cells, ranges from 15 to $500 \mu \mathrm{g} / \mathrm{mL}$ [20]. There is a significant variability of used concentrations, but higher AGEs levels generally reflect the physiological plasma levels found in patients suffering from multiple diseases. Indeed, AGEs-albumin concentration in diabetic patients has been shown to range from $50 \mathrm{up}$ to $400 \mu \mathrm{g} / \mathrm{mL}$ [30]. AGEs levels can rise to concentrations up to $200 \mu \mathrm{g} / \mathrm{mL}$ in patients suffering from cardiovascular diseases [31,32]. In patients with early-stage Alzheimer's disease, lower AGEs concentrations in the nanoscale range, are also reported [33]. However, because of the different analytical methods used for measuring AGEs, and the heterogeneity of different types of AGEs, estimation of reliable AGEs concentrations in vivo remains technically challenging and is probably an underestimation [34].

\subsection{AGEs Have a Negative Impact on CASCs Properties}

Even if CASCs transplantation shows promising potential for cardiac regeneration post-MI, survival and regenerative capacity of cells remains an issue. Ischemic areas are known to be a hostile environment with increased levels of oxidative stress, inflammation, and fibrosis combined with increased AGEs tissue levels. Whether AGEs would affect the regenerative capacity of CASCs was unknown but could be important knowledge in the context of cardiac regeneration and the promising regenerative capacities of CASCs [12]. In our study, we show that AGEs impair CASCs survival, proliferation, and migration in vitro, in a concentration- and time-dependent manner. Furthermore, exposure to AGEs leads to a gradual increase in CASCs apoptosis. Our data are in line with studies examining the effect of AGEs on multiple types of other stem cells, in which proliferative capacity is altered and apoptosis is increased [20]. Indeed, Zhu et al. demonstrated a significant decrease in EPCs proliferation after exposure to different concentrations of AGEs [16]. The same effect was evaluated by Sun et al. also in EPCs, where an increase in apoptotic rate was mediated by p38 MAPK pathway activation [35]. NSCs exposed to AGEs resulted in a dose-dependent reduction of stem cell proliferation, mediated via the PPAR $\gamma$ pathway [36]. In adipose tissue-derived stem cells (ADSCs), an increase in caspase 3 activation leads to an increased apoptotic rate [37]. Yang et al. reported lower proliferation and migration capacities in MSCs, in an AGEs concentration-dependent way. This effect was mediated via excessive ROS production [18]. Whether the deleterious effects on CASCs, a very different stem cell population of cardiac origin, are also mediated through excessive ROS production, remains to be determined.

It has been shown that the underlying mechanisms in which AGEs execute their negative effects on organ function are dependent and/or independent of RAGE receptor activation [15]. Studies in many stem cells types show that AGEs mediate their effects mainly through the activation of RAGE or other apoptotic pathways [20]. RAGE activation by AGEs causes activation of MAPK, which leads to phosphorylation of JNK and p38 [38]. These phosphorylated proteins increase the transcription of different pro-apoptotic transcription factors in the nucleus, leading to an increase in apoptosis. Next to that, caspase 
pathways can be activated, causing AGEs-induced apoptosis [39]. Follow-up studies remain necessary to unravel the molecular mechanisms by which the downstream effects of AGEs are induced in CASCs. However, we have shown that upon RAGE-blocking by FPS-ZM1, the observed effects of AGEs on CASCs were blunted. Therefore, our data strongly indicate that AGEs mediate their effects on CASCs likely through binding and activation of RAGE. Whether the Jak/STAT, PI3K/Akt, MAPK, excessive ROS production, or other signaling pathways are involved, remains to be further identified. Our data are also in line with the work described by Zhang et al., where FPS-ZM1 also reversed the negative effects of AGEs in ADSCs by blocking RAGE, further confirming the important role of RAGE activation as a mediator of the deleterious effects caused by AGEs [40].

\subsection{Future Perspectives for Anti-AGEs Therapies for Cardiovascular Diseases and Current Limitations}

In vivo confirmation on the use of anti-AGEs therapies and their potential added value to stem cell transplantation after MI need to be confirmed in an animal model before this can be translated to the clinic. It has been shown in multiple in vitro studies that the PPAR $\gamma$ inhibitor rosiglitazone [41,42], MAPK inhibitors [18,35,43], or antioxidants [44] can attenuate the AGEs-mediated effects on stem cells. However, their influence in vivo as a therapeutic intervention in combination with stem cell transplantation has never been addressed so far. There are multiple strategies to lower AGEs levels in the body. Pyridoxamine (PM) is an inhibitor of AGEs formation by decreasing the Amadori-to-AGEs conversion and scavenging carbonyl compounds. The efficacy as well as the safety of PM treatment has been demonstrated in clinical trials with diabetic patients [45]. However, a clinical trial of NephroGenex in 2014, testing Pyridorin ${ }^{\circledR}$ (i.e., PM) as an anti-diabetic therapy, was stopped due to financial issues [46]. No other clinical trials are currently investigating PM as a therapy. However, inhibiting AGEs formation with PM could be a strategy to improve stem cell potential for cardiac regenerative purposes. In addition, other inhibitors of AGEs formation, like aminoguanidine, could be used in the future to lower AGEs levels after MI. The ACTION II clinical trial showed the efficacy of aminoguanidine in diabetic patients. While aminoguanidine failed to significantly reduce the primary endpoint of doubling the time to reach maximum serum creatinine levels in these patients, other clinically important effects on the complications of diabetes, such as reduction in proteinuria and circulatory lipid concentrations, were shown. However, due to reversible adverse effects such as the induction of autoantibodies, flu-like symptoms, and anemia, this trial was terminated and translation into the clinic remains limited [47,48]. In addition, using antioxidants such as $\mathrm{N}$-acetyl-L-cysteine (NAC) or glutathione as a supplement to our diet could provide some beneficial outcome for stem cell therapy, as they increase genomic stability, improve adhesion, and stimulate stem cell proliferation [49]. However, cell-specific actions differ between stem cell types, and dose-response clinical trials are needed to evaluate their therapeutic efficacy when used in combination with stem cell transplantation. Another option is to break down AGEs with ALT-711 therapy. ALT-711 is able to cleave carbon-carbon bounds between carbonyls, thereby breaking cross-links in AGEs molecules. However, several clinical trials could not confirm the beneficial effects of ALT-711 observed in animal studies. Furthermore, inhibitors of RAGE (like FPS-ZM1) or inhibitors of downstream molecules in the RAGE pathway can interfere in the AGEs/RAGE cell signaling axis, thereby blocking AGEs-mediated effects in stem cells. The efficacy of different types of small molecules and inhibitors to block AGEs in stem cells has been demonstrated in multiple in vitro experiments $[18,35,41-44]$, but has never been tested before in animal models. Therefore, we can only hypothesize that these inhibitors are efficient in blocking AGEs in an in vivo situation, but proof-of-concept experiments are needed. Finally, another option in blocking AGEs in combination with stem cell therapy, is genetically modifying stem cells itself. Overexpression of sRAGE is known to enhance AGEs scavenging (and other RAGE ligands like amyloid- $\beta$ ) to improve the effectiveness of cell therapy. This has been shown in sRAGE-secreting MSCs as a therapy for Alzheimer's disease [50,51], arthritis [52], and Parkinson's disease [53]. sRAGE secreting MSCs survived 
longer, had enhanced migration capacity, were better protected against apoptosis, and had anti-inflammatory properties. Also, downregulation of RAGE, thereby desensitizing the stem cells for AGEs, could be an option in improving functionality of the cells. Whether these strategies could also be applicable in the setting of MI and cardiac repair remains to be investigated. To summarize, all these strategies aim at tackling AGEs to improve stem cell functionality and retention. However, these therapeutic options remain hypothetical and need to be investigated in vivo in combination with CASCs therapy before this can be translated into the clinical setting.

\section{Conclusions}

We found that AGEs had a time- and concentration-dependent, gradual effect on CASCs' properties, by increasing apoptosis and by reducing survival, proliferation, and migration in vitro. The working mechanisms behind these effects remain to be further investigated, although we have shown that RAGE activation is an important contributor of these AGEs-related negative effects. Whether targeting AGEs in vivo could improve CASCs' therapeutic capacity after MI, remains to be further investigated.

Supplementary Materials: The following are available online at https://www.mdpi.com/article/ 10.3390/jcm10132964/s1, Figure S1: Effect of BSA over time on CASCs proliferation and survival, Figure S2: Effect of ranging concentrations of the RAGE inhibitor (FPS-ZM1) on CASCs proliferation and survival.

Author Contributions: Conceptualization, L.E., E.H., A.B., D.D. and V.B.; methodology, L.E. and E.H.; validation, L.E. and E.H.; formal analysis, L.E., E.H. and D.D.; investigation, L.E., E.H. and D.D.; data curation, L.E., E.H., D.D. and V.B.; writing-original draft preparation, L.E., E.H., D.D. and V.B.; writing-review and editing, L.E., E.H., J.-L.R., A.B., M.H., D.D. and V.B.; visualization, L.E.; supervision, J.-L.R., A.B., M.H., D.D. and V.B.; project administration, L.E., D.D. and V.B.; funding acquisition, M.H., D.D. and V.B. All authors have read and agreed to the published version of the manuscript.

Funding: This work was supported by a Bijzonder onderzoeksfonds (BOF) grant from Hasselt University, grant number: 16NI05BOF.

Institutional Review Board Statement: The animal study was conducted in accordance with the EU Directive 2010/63/EU for animal experiments and approved by the Local Ethical Committee for Animal Experimentation of UHasselt, Belgium, Diepenbeek; ID 201919K.

Data Availability Statement: The data presented in this study are available on request from the corresponding author.

Acknowledgments: The graphical abstract was created using images from Servier Medical Art Commons Attribution 3.0 Unported License (http:/ / smart.servier.com (accessed on 29 June 2021)). Servier Medical Art by Servier is licensed under a Creative Commons Attribution 3.0 Unported License.

Conflicts of Interest: The authors declare no conflict of interest.

\section{References}

1. Jayaraj, J.C.; Davatyan, K.; Subramanian, S.; Priya, J. Epidemiology of Myocardial Infarction. Myocard. Infarct. 2019. [CrossRef]

2. Heusch, G.; Gersh, B.J. The pathophysiology of acute myocardial infarction and strategies of protection beyond reperfusion: A continual challenge. Eur. Heart J. 2017, 38, 774-784. [CrossRef]

3. Hendrikx, M.; Fanton, Y.; Willems, L.; Daniels, A.; Declercq, J.; Windmolders, S.; Hensen, K.; Koninckx, R.; Jamaer, L.; Dubois, J.; et al. From bone marrow to cardiac atrial appendage stem cells for cardiac repair: A review. Curr. Med. Chem. 2016, 23, 2421-2438. [CrossRef]

4. Koninckx, R.; Daniëls, A.; Windmolders, S.; Mees, U.; Macianskiene, R.; Mubagwa, K.; Steels, P.; Jamaer, L.; Dubois, J.; Robic, B.; et al. The cardiac atrial appendage stem cell: A new and promising candidate for myocardial repair. Cardiovasc. Res. 2013, 97, 413-423. [CrossRef]

5. Yeghiazarians, Y.; Zhang, Y.; Prasad, M.; Shih, H.; Saini, S.A.; Takagawa, J.; Sievers, R.E.; Wong, M.L.; Kapasi, N.K.; Mirsky, R.; et al. Injection of Bone Marrow Cell Extract into Infarcted Hearts Results in Functional Improvement Comparable to Intact Cell Therapy. Mol. Ther. 2009, 17, 1250-1256. [CrossRef] [PubMed] 
6. Belostotskaya, G.; Hendrikx, M.; Galagudza, M.; Suchkov, S. How to Stimulate Myocardial Regeneration in Adult Mammalian Heart: Existing Views and New Approaches. BioMed Res. Int. 2020, 2020, 7874109. [CrossRef] [PubMed]

7. Gentry, T.; Foster, S.; Winstead, L.; Deibert, E.; Fiordalisi, M.; Balber, A. Simultaneous isolation of human BM hematopoietic, endothelial and mesenchymal progenitor cells by flow sorting based on aldehyde dehydrogenase activity: Implications for cell therapy. Cytotherapy 2007, 9, 259-274. [CrossRef] [PubMed]

8. Jiang, F.; Qiu, Q.; Khanna, A.; Todd, N.W.; Deepak, J.; Xing, L.; Wang, H.; Liu, Z.; Su, Y.; Stass, S.A.; et al. Aldehyde Dehydrogenase 1 Is a Tumor Stem Cell-Associated Marker in Lung Cancer. Mol. Cancer Res. 2009, 7, 330-338. [CrossRef]

9. Moreb, J.S. Aldehyde Dehydrogenase as a Marker for Stem Cells. Curr. Stem Cell Res. Ther. 2008, 3, 237-246. [CrossRef]

10. Chen, C.-H.; Sun, L.; Mochly-Rosen, D. Mitochondrial aldehyde dehydrogenase and cardiac diseases. Cardiovasc. Res. 2010, 88, 51-57. [CrossRef]

11. Windmolders, S.; Willems, L.; Daniëls, A.; Linsen, L.; Fanton, Y.; Hendrikx, M.; Koninckx, R.; Rummens, J.-L.; Hensen, K. Clinical-scalein vitroexpansion preserves biological characteristics of cardiac atrial appendage stem cells. Cell Prolif. 2015, 48, 175-186. [CrossRef]

12. Fanton, Y.; Robic, B.; Rummens, J.-L.; Daniëls, A.; Windmolders, S.; Willems, L.; Jamaer, L.; Dubois, J.; Bijnens, E.; Heuts, N.; et al. Cardiac atrial appendage stem cells engraft and differentiate into cardiomyocytes in vivo: A new tool for cardiac repair after MI. Int. J. Cardiol. 2015, 201, 10-19. [CrossRef]

13. Deluyker, D.; Ferferieva, V.; Driesen, R.B.; Verboven, M.; Lambrichts, I.; Bito, V. Pyridoxamine improves survival and limits cardiac dysfunction after MI. Sci. Rep. 2017, 7, 16010. [CrossRef] [PubMed]

14. Singh, R.; Barden, A.; Mori, T.; Beilin, L. Advanced glycation end-products: A review. Diabetologia 2001, 44, 129-146. [CrossRef]

15. Deluyker, D.; Evens, L.; Bito, V. Advanced glycation end products (AGEs) and cardiovascular dysfunction: Focus on high molecular weight AGEs. Amino Acids 2017, 49, 1535-1541. [CrossRef] [PubMed]

16. Zhu, J.; Yang, K.; Jing, Y.; Du, R.; Zhu, Z.; Lu, L.; Zhang, R. The effects of low-dose Nepsilon-(carboxymethyl)lysine (CML) and Nepsilon-(carboxyethyl)lysine (CEL), two main glycation free adducts considered as potential uremic toxins, on endothelial progenitor cell function. Cardiovasc. Diabetol. 2012, 11, 90. [CrossRef] [PubMed]

17. Hartog, J.W.L.; Voors, A.A.; Bakker, S.J.L.; Smit, A.J.; Van Veldhuisen, D.J. Advanced glycation end-products (AGEs) and heart failure: Pathophysiology and clinical implications. Eur. J. Heart Fail. 2007, 9, 1146-1155. [CrossRef]

18. Yang, K.; Wang, X.Q.; He, Y.S.; Lu, L.; Chen, Q.J.; Liu, J.; Shen, W.F. Advanced glycation end products induce chemokine/cytokine production via activation of p38 pathway and inhibit proliferation and migration of bone marrow mesenchymal stem cells. Cardiovasc. Diabetol. 2010, 9, 66. [CrossRef]

19. Chen, Q.; Dong, L.; Wang, L.; Kang, L.; Xu, B. Advanced glycation end products impair function of late endothelial progenitor cells through effects on protein kinase Akt and cyclooxygenase-2. Biochem. Biophys. Res. Commun. 2009, 381, 192-197. [CrossRef]

20. Evens, L.; Beliën, H.; Deluyker, D.; Bronckaers, A.; Gervois, P.; Hendrikx, M.; Bito, V. The Impact of Advanced Glycation End-Products (AGEs) on Proliferation and Apoptosis of Primary Stem Cells: A Systematic Review. Stem Cells Int. 2020, 2020, 8886612. [CrossRef]

21. Deluyker, D.; Ferferieva, V.; Noben, J.-P.; Swennen, Q.; Bronckaers, A.; Lambrichts, I.; Rigo, J.-M.; Bito, V. Cross-linking versus RAGE: How do high molecular weight advanced glycation products induce cardiac dysfunction? Int. J. Cardiol. 2016, 210, 100-108. [CrossRef] [PubMed]

22. Gervois, P.; Ratajczak, J.; Wolfs, E.; Vangansewinkel, T.; Dillen, Y.; Merckx, G.; Bronckaers, A.; Lambrichts, I. Preconditioning of Human Dental Pulp Stem Cells with Leukocyte- and Platelet-Rich Fibrin-Derived Factors Does Not Enhance Their Neuroregenerative Effect. Stem Cells Int. 2019, 2019, 8589149. [CrossRef] [PubMed]

23. Monaco, M.L.; Gervois, P.; Beaumont, J.; Clegg, P.; Bronckaers, A.; Vandeweerd, J.-M.; Lambrichts, I. Therapeutic Potential of Dental Pulp Stem Cells and Leukocyte- and Platelet-Rich Fibrin for Osteoarthritis. Cells 2020, 9, 980. [CrossRef]

24. Qiu, H.; Li, W.-P.; Shen, X.-H.; Guo, X.-Y.; Hua, B.; Li, H.-W. Dynamic fluctuations of advanced glycation end products and its $\mathrm{C}$-terminal truncated receptor level in patients with acute ST-segment elevation myocardial infarction and undergoing diabetes or not: A retrospective study. Medicine 2018, 97, e11278. [CrossRef] [PubMed]

25. Fishman, S.L.; Sonmez, H.; Basman, C.; Singh, V.; Poretsky, L. The role of advanced glycation end-products in the development of coronary artery disease in patients with and without diabetes mellitus: A review. Mol. Med. 2018, 24, 59. [CrossRef]

26. Greven, W.L.; Smit, J.M.; Rommes, J.H.; Spronk, P.E. Accumulation of advanced glycation end (AGEs) products in intensive care patients: An observational, prospective study. BMC Clin. Pathol. 2010, 10, 4. [CrossRef] [PubMed]

27. Celec, P.; Hodosy, J.; Jani, P.; Janega, P.; Kúdela, M.; Kalousova, M.; Holzerová, J.; Parrak, V.; Halčák, L.; Zima, T.; et al. Advanced glycation end products in myocardial reperfusion injury. Heart Vessels 2011, 27, 208-215. [CrossRef]

28. Yang, J.; Zhang, F.; Shi, H.; Gao, Y.; Dong, Z.; Ma, L.; Sun, X.; Li, X.; Chang, S.; Wang, Z.; et al. Neutrophil-derived advanced glycation end products-N $\varepsilon$-(carboxymethyl) lysine promotes RIP3-mediated myocardial necroptosis via RAGE and exacerbates myocardial ischemia/reperfusion injury. FASEB J. 2019, 33, 14410-14422. [CrossRef]

29. Son, M.; Kang, W.C.; Oh, S.; Bayarsaikhan, D.; Ahn, H.; Lee, J.; Park, H.; Lee, S.; Choi, J.; Lee, H.S.; et al. Advanced glycation end-product (AGE)-albumin from activated macrophage is critical in human mesenchymal stem cells survival and post-ischemic reperfusion injury. Sci. Rep. 2017, 7, 11593. [CrossRef] 
30. Miura, J.; Yamagishi, S.-I.; Uchigata, Y.; Takeuchi, M.; Yamamoto, H.; Makita, Z.; Iwamoto, Y. Serum levels of noncarboxymethyllysine advanced glycation endproducts are correlated to severity of microvascular complications in patients with Type 1 diabetes. J. Diabetes Complicat. 2003, 17, 16-21. [CrossRef]

31. Willemsen, S.; Hartog, J.W.; van Veldhuisen, D.J.; van der Meer, P.; Rozé, J.-C.; Jaarsma, T.; Schalkwijk, C.; van der Horst, I.C.; Hillege, H.L.; Voors, A.A. The role of advanced glycation end-products and their receptor on outcome in heart failure patients with preserved and reduced ejection fraction. Am. Heart J. 2012, 164, 742-749.e3. [CrossRef]

32. Deluyker, D.; Evens, L.; Beliën, H.; Bito, V. Acute exposure to glycated proteins reduces cardiomyocyte contractile capacity. Exp. Physiol. 2019, 104, 997-1003. [CrossRef]

33. Egorska-Ciebiada, M.; Esaryusz-Wolska, M.; Eborkowska, A.; Eciebiada, M.; Eloba, J. C-Reactive Protein, Advanced Glycation End Products, and Their Receptor in Type 2 Diabetic, Elderly Patients with Mild Cognitive Impairment. Front. Aging Neurosci. 2015, 7, 209. [CrossRef]

34. Rabbani, N.; Thornalley, P. Measurement of methylglyoxal by stable isotopic dilution analysis LC-MS/MS with corroborative prediction in physiological samples. Nat. Protoc. 2014, 9, 1969-1979. [CrossRef] [PubMed]

35. Sun, C.; Liang, C.; Ren, Y.; Zhen, Y.; He, Z.; Wang, H.; Tan, H.; Pan, X.; Wu, Z. Advanced glycation end products depress function of endothelial progenitor cells via p38 and ERK $1 / 2$ mitogen-activated protein kinase pathways. Basic Res. Cardiol. 2008, 104, 42-49. [CrossRef]

36. Wang, S.-H.; Sun, Z.-L.; Guo, Y.-J.; Yuan, Y.; Li, L. PPAR $\gamma$-mediated advanced glycation end products regulation of neural stem cells. Mol. Cell. Endocrinol. 2009, 307, 176-184. [CrossRef] [PubMed]

37. Wang, Z.; Li, H.; Zhang, D.; Liu, X.; Zhao, F.; Pang, X.; Wang, Q. Effect of advanced glycosylation end products on apoptosis in human adipose tissue-derived stem cells in vitro. Cell Biosci. 2015, 5, 3. [CrossRef] [PubMed]

38. Ma, C.; Zhang, Y.; Li, Y.-Q.; Chen, C.; Cai, W.; Zeng, Y.-L. The Role of PPAR $\gamma$ in Advanced Glycation End Products-Induced Inflammatory Response in Human Chondrocytes. PLoS ONE 2015, 10, e0125776. [CrossRef] [PubMed]

39. Wang, Z.; Li, H.; Guo, R.; Wang, Q.; Zhang, D. Antioxidants inhibit advanced glycosylation end-product-induced apoptosis by downregulation of miR-223 in human adipose tissue-derived stem cells. Sci. Rep. 2016, 6, 23021. [CrossRef] [PubMed]

40. Zhang, M.; Li, Y.; Rao, P.; Huang, K.; Luo, D.; Cai, X.; Xiao, J. Blockade of receptors of advanced glycation end products ameliorates diabetic osteogenesis of adipose-derived stem cells through DNA methylation and Wnt signalling pathway. Cell Prolif. 2018, 51, e12471. [CrossRef]

41. Wang, S.-H.; Guo, Y.-J.; Yuan, Y.; Li, L.; Li, F.-F.; Ye, K.-P.; Huang, Y. PPAR $\gamma$-mediated advanced glycation end products regulate neural stem cell proliferation but not neural differentiation through the BDNF-CREB pathway. Toxicol. Lett. 2011, 206, 339-346. [CrossRef]

42. Liang, C.; Ren, Y.; Tan, H.; He, Z.; Jiang, Q.; Wu, J.; Zhen, Y.; Fan, M.; Wu, Z. Rosiglitazone via upregulation of Akt/eNOS pathways attenuates dysfunction of endothelial progenitor cells, induced by advanced glycation end products. Br. J. Pharmacol. 2009, 158, 1865-1873. [CrossRef] [PubMed]

43. Shen, C.; Li, Q.; Zhang, Y.C.; Ma, G.; Feng, Y.; Zhu, Q.; Dai, Q.; Chen, Z.; Yao, Y.; Chen, L.; et al. Advanced glycation endproducts increase EPC apoptosis and decrease nitric oxide release via MAPK pathways. Biomed. Pharmacother. 2010, 64, 35-43. [CrossRef]

44. Zeng, Y.-C.; Peng, L.-S.; Zou, L.; Huang, S.-F.; Xie, Y.; Mu, G.-P.; Zeng, X.-H.; Zhou, X.-L. Protective effect and mechanism of lycopene on endothelial progenitor cells (EPCs) from type 2 diabetes mellitus rats. Biomed. Pharmacother. 2017, 92, 86-94. [CrossRef]

45. Dwyer, J.P.; Greco, B.A.; Umanath, K.; Packham, D.; Fox, J.W.; Peterson, R.; Broome, B.R.; Greene, L.E.; Sika, M.; Lewis, J.B. Pyridoxamine Dihydrochloride in Diabetic Nephropathy (PIONEER-CSG-17): Lessons Learned from a Pilot Study. Nephron 2014, 129, 22-28. [CrossRef] [PubMed]

46. Borg, D.J.; Forbes, J.M. Targeting advanced glycation with pharmaceutical agents: Where are we now? Glycoconj. J. 2016, 33, 653-670. [CrossRef]

47. Bolton, W.K.; Cattran, D.C.; Williams, M.E.; Adler, S.G.; Appel, G.B.; Cartwright, K.; Foiles, P.G.; Freedman, B.I.; Raskin, P.; Ratner, R.E.; et al. Randomized Trial of an Inhibitor of Formation of Advanced Glycation End Products in Diabetic Nephropathy. Am. J. Nephrol. 2004, 24, 32-40. [CrossRef]

48. Freedman, B.I.; Wuerth, J.-P.; Cartwright, K.; Bain, R.P.; Dippe, S.; Hershon, K.; Mooradian, A.D.; Spinowitz, B.S. Design and Baseline Characteristics for the Aminoguanidine Clinical Trial in Overt Type 2 Diabetic Nephropathy (ACTION II). Control. Clin. Trials 1999, 20, 493-510. [CrossRef]

49. Shaban, S.; El-Husseny, M.W.A.; Abushouk, A.I.; Salem, A.M.A.; Mamdouh, M.; Abdel-Daim, M.M. Effects of Antioxidant Supplements on the Survival and Differentiation of Stem Cells. Oxid. Med. Cell. Longev. 2017, 2017, 5032102. [CrossRef] [PubMed]

50. Oh, S.; Son, M.; Choi, J.; Lee, S.; Byun, K. sRAGE prolonged stem cell survival and suppressed RAGE-related inflammatory cell and T lymphocyte accumulations in an Alzheimer's disease model. Biochem. Biophys. Res. Commun. 2018, 495, 807-813. [CrossRef]

51. Son, M.; Oh, S.; Park, H.; Ahn, H.; Choi, J.; Kim, H.; Lee, H.S.; Lee, S.; Park, H.-J.; Kim, S.U.; et al. Protection against RAGEmediated neuronal cell death by sRAGE-secreting human mesenchymal stem cells in 5xFAD transgenic mouse model. Brain Behav. Immun. 2017, 66, 347-358. [CrossRef] [PubMed] 
52. Park, M.-J.; Lee, S.H.; Moon, S.-J.; Lee, J.-A.; Lee, E.-J.; Kim, E.-K.; Park, J.-S.; Lee, J.; Min, J.-K.; Kim, S.J.; et al. Overexpression of soluble RAGE in mesenchymal stem cells enhances their immunoregulatory potential for cellular therapy in autoimmune arthritis. Sci. Rep. 2016, 6, 35933. [CrossRef] [PubMed]

53. Lee, J.; Bayarsaikhan, D.; Arivazhagan, R.; Park, H.; Lim, B.; Gwak, P.; Jeong, G.-B.; Lee, J.; Byun, K.; Lee, B. CRISPR/Cas9 Edited sRAGE-MSCs Protect Neuronal Death in Parkinson's Disease Model. Int. J. Stem Cells 2019, 12, 114-124. [CrossRef] [PubMed] 